\title{
Flush closure of the sapheno-femoral junction with LASER
}

\section{LASER CROSSECTOMY}

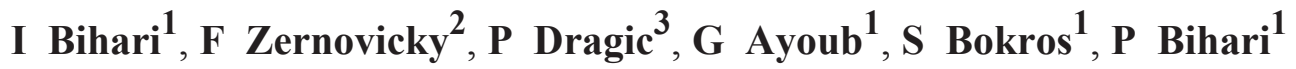 \\ ${ }^{1}$ A and B Clinic Budapest, Hungary. 42-44, Nepszinhaz utca, Budapest, Hungary 1081. Tel: +36-30-9605-855 \\ ${ }^{2}$ Klinika Cievnej Chirurgie. Národný Ústav Srdcových a Cievných Chorôb. Bratislava, Slovakia

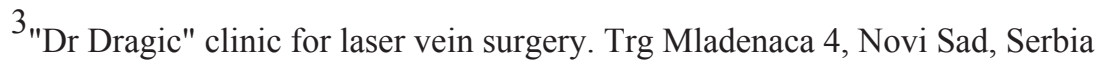

submitted: Jun 25, 2019, accepted: Nov 04, 2019, EPub Ahead of Print: Dec 02, 2019

Conflict of interest: None

DOI: 10.24019/jtavr.69 - Corresponding author:Prof. Imre Bihari, imre.bihari.dr@gmail.com

(C) 2018 Fondazione Vasculab impresa sociale ONLUS. All rights reserved.

\begin{abstract}
AIM

During laser ablation, the terminal segment and tributaries of that part of the GSV are left patent. So the saphenofemoral junction (SFJ), near the epigastric vein is spared. This technique resulted in a $13.8 \%$ early recurrency rate for our patients. Could the results improve if the terminal part of the GSV and tributaries were closed with laser?

PATIENTS

In a retrospective study all patients who underwent endovenous laser obliteration of the GSV more than 1 year previously were investigated clinically and with ultrasound. 83 patients were checked between 1 and 2 years (median interval 14 months) after a modified technique laser ablation.

METHODS

The bare tip of the laser fibre was held nearer than recommended which means $1 \mathrm{~cm}$ from the femoral vein. A $980 \mathrm{~nm}$ laser equipment was employed and the median Linear Endovenous Energy Density (LEED) was $179 \mathrm{~J} / \mathrm{cm}$. $5 \mathrm{ml} / \mathrm{cm}$ cooled $\left(3-5^{\circ} \mathrm{C}\right)$ tumescent local anaesthetic was used.

RESULTS
\end{abstract}

\section{Introduction}

Most vascular surgeons and phlebologists agree that the treatment of the sapheno-femoral junction (SFJ) is
One accessory anterior recurrent varicosity in connection to the SFJ (1.2\%) was observed. Further US findings are: in 33 limbs $(39.7 \%)$ flush closure of the SFJ without any patent tributaries were in $11(13.2 \%)$ flush occlusion with direct opening of a tributary into the junction or femoral vein. In 39 limbs $(47.0 \%)$ there was a short (median length $7 \mathrm{~mm}$ ) saphenous stump. There were no thromboembolic or any other serious complications.

\section{CONCLUSIONS}

The flush closure and short saphenous stump of GSV both gave better early recurrency results than the long saphenous stump technique. There was no sign of recanalisation of the GSV and only 1 accessory anterior varicosity. There was no sign of neovascularisation during our follow-up period. This means our early postoperative results are better with this technique than with the formerly used GSV terminal part and epigastric vein saving method. There is not a higher risk of complications if the junction is occluded flush with the femoral vein. Limitations of this study are the short follow-up period and few cases.

Keywords Varicose veins, laser ablation, recurrency, SFJ, tributaries

important in the prevention of early and late recurrencies of great saphenous vein (GSV) varicosity ${ }^{1,2,3}$. Following the surgical operation (crossectomy and stripping), untreated tributaries and new ones (neovascularisation) around the 
junction are the main sources of recurrent varicosity 4,5 , 6 . During laser ablation, the junction part (usually $2 \mathrm{~cm}$ ) of the GSV and tributaries are left patent ${ }^{7,8}$. Colleagues converting from classic to laser surgery often ask whether these patent tributaries around the junction could cause recurrent varicosity. A metaanalysis of laser surgery results really showed a high recurrency rate from these side branches 9,10 .

We subdivided our experience into two subsequent periods, according to the adopted method to treat the SFJ. In the first year (1 April 2007- 1 April 2008) varicose vein laser surgery was performed according to descriptions, leaving a $2 \mathrm{~cm}$ long distance between the femoral vein and the tip of the laser fibre. This technique resulted in a $13.8 \%$ early recurrency rate. Recurrency patterns were recanalisations and accessory anterior vein dilatations. In this study we were studying the following problem: what happens if the GSV is occluded flush with the femoral vein and side branches are also closed with laser?

\section{Patients}

In the second period between 1 April 2008 and 31 December 2010, 102 laser ablations were performed with a different technique on varicose GSVs which were suitable for our study called the flush closure technique. Of these 102 legs, 83(81.4\%) came back at the 1-year follow-up, thus they could be examined after more than 1 year, (the longest 21 months following their surgery, median interval 14 months).

The pre-procedural diameter ranged between 4 and $23 \mathrm{~mm}$ (median $8 \mathrm{~mm}$ ) $3 \mathrm{~cm}$ below the junction.
Aneurysmatic GSVs were also included. According to CEAP classification, all the patients belonged to the $\mathrm{C} 2$ C6 clinical classes.

\section{Methods}

A $980 \mathrm{~nm}$ Biolitec laser equipment on 13 Watt and $600 \mu \mathrm{m}$ bare fibre was used. The tip of the laser fibre was placed $1 \mathrm{~cm}$ from the SFJ. Mean LEED was higher than usual, $179 \mathrm{~J} / \mathrm{cm}$. The fibre was pulled manually. Around the GSV, from the canulation puncture site to the SFJ, cooled $\left(3-5{ }^{\circ} \mathrm{C}\right) 0.1 \%$ Lidocain and Adrenaline tumescent local anaesthetic was employed $(5 \mathrm{ml} / \mathrm{cm})$. General anaesthesia (Propofol) without intubation was also used in all cases. For removal of side branches and interruption of perforator veins along the limb, a saw-knife, Varady's hook and sclerotherapy were used ${ }^{11,12}$.

Following surgery, patients were observed for 3 hours and afterwards discharged. Chemical thrombosis prophylaxis was not used. Excentric compression with bandages was applied for two weeks, day and night, and a stocking during the day for a further two weeks. In other regards, we followed the described method $8,13,14$.

Follow-up was planned at 1, 7 and 14 days and 1, 3, 6 and 12 months and every subsequent 6 months and the operated legs were examined clinically and with US (GE Vingmed, System Five). Clinically residual and new varicose veins along the limb, and in the groin region, were additionally examined with an ultrasound examination focused on the patency of deep veins, SFJ patency, tributaries, the distance of the occlusion from the the femoral vein and the occlusion of the treated part of the GSV.

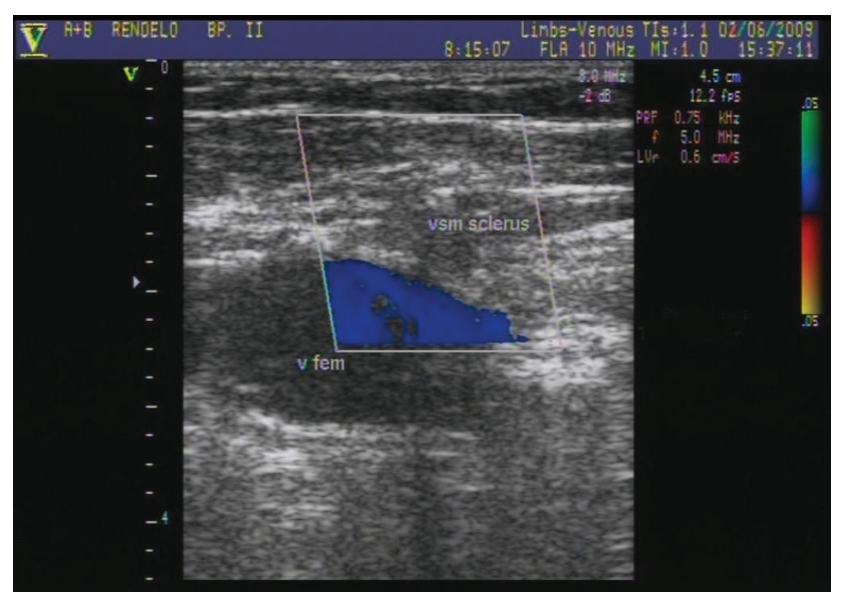

Figure 1 - Closure of SFJ is flush with the femoral vein. One year after laser surgery.

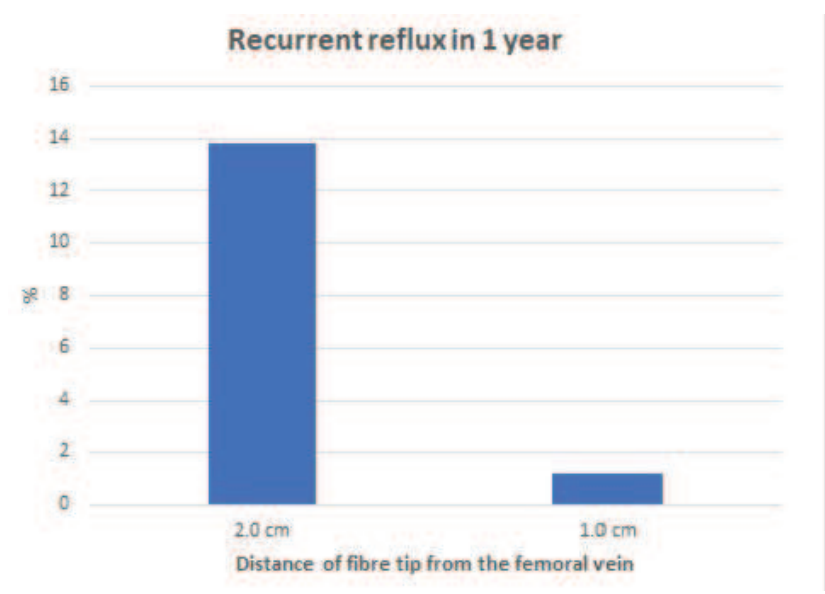

Figure 2 - Rate of recurrency in both groups, 1 year results. Distance of fibre tip from the femoral vein. 


\section{Results}

One accessory anterior varicosity recurrency $(1.2 \%)$ was observed. Further US examination results of the SFJ were ranked into three categories:

\section{Ultrasound patterns in SFJ}

- $\quad$ (a) flush occlusion of GSV with the femoral vein (EHIT 1) with the closure of tributaries 33 limbs, 39.8\%) (Fig. 1). In 3 of these cases the thrombus protruded into the femoral vein (EHIT 2). This protrusion dissolved spontaneously within 3 months without complications.

- (b) flush occlusion with opening of a patent tributary into the junction or directly into the femoral vein without a saphenous stump (11 limbs, 13.3\%).

- $\quad$ (c) occlusion with 1-26 mm long saphenous stump (median length $7 \mathrm{~mm}$ ) and 1-3 patent side branches (39 limbs, $47.0 \%$ ). In this category, the patent part of the saphenous vein typically extended from the femoral vein to one or more tributaries. In 3 cases the patent part was even longer.

\section{Further findings:}

- $\quad$ 1) We did not find any dilated or varicose side branches or reticular veins around the groin or along the limb.

- 2) The SFJ tributaries did not become dilated, elongated or tortuous.

- 3) No signs of neovascularisation were observed at all.

- $\quad$ 4) Treated GSV stems were occluded as long as laser irradiation was performed, there was no recanalisation.

- 5) There were no serious complications e.g. deep venous thrombosis or pulmonary embolism.

Elimination of reflux and closure of the GSV were successful just after the intervention and also at the last check-up in every case (98.8\%) (Fig. 2).

There were no serious complications (deep venous thrombosis, pulmonary embolism, septic complications, etc.), only temporary ecchymosis in every case, pigmentation in 3 limbs, ankle swelling in 2 cases which disappeared following one additional month of bandaging. There was temporary hypoaesthesia combined with hyperaesthesia in 6 cases $(7.2 \%)$, on the distal part of the thigh where the laser was used. Later, in other cases 2 pulmonary embolisms were found, so LMWH prophylaxis was introduced in every subsequent case.

\section{Discussion}

At first sight, varicose veins laser ablation is just a method that replaces the stripping part of the classic surgical modality, which is why some colleagues proposed separate surgical interruption of the $\mathrm{SFJ}^{15,16,17}$. However, laser closure of the saphenous stem is one of its effects, because laser surgery has an effect on the SFJ as well ${ }^{8 \text {, }}$ $13,18,19$. In many cases the anatomical results of the laser intervention at the SFJ resembles the Trendelenburg operation (distal ligation), which has been criticised for many decades. In some cases laser operation gives results which are similar to crossectomy. It seems that laser ablation combined with surgical crossectomy did not improve the results $20,21,22$. Our study focuses mainly on the question of what happens if the anatomical results of laser ablation are similar to crossectomy. Are the clinical results better or worse?

What could be the topical technique for flush occlusions? We think there are two factors, one being the higher delivered energy. The other is, that the fibre tip position is nearer to the femoral vein: at $1 \mathrm{~cm}^{8,13}$, Theivacumar et al. also found that it can cause flush occlusion $^{23}$.

Why does the closure stops at the junction? The bare tip laser fibre delivers the laser beam mainly in front, although the effect of the laser within the blood is limited ${ }^{14}$. On the other hand, the reason that the occlusion stops at the junction of the GSV, is because the diameter of the femoral vein is bigger than that of the GSV. The femoral vein is wider and would require much more energy to cause any occlusion there. A further reason could be the higher speed flow in the femoral vein than in the saphenous vein ${ }^{24,} 25$. The tumescent solution also has some mechanical effect, because it compresses the saphenous vein, so it does not let out too much heated blood and bubbles, or slows their movement towards the femoral vein. There is a further mechanism which safeguards the femoral vein: the tip of the laser fibre is held $1 \mathrm{~cm}$ away, and around the terminal segment there is cold tumescent solution which cools down the heated blood and steam bubbles before entering the femoral vein. Also, the direct contact of the tip of the fibre only comes up to this segment of the $\mathrm{GSV}^{26}$.

We should also mention the special case in which the thrombus protrudes into the femoral vein (EHIT 2). 
This was our finding in 3 cases in which the protrusion disappeared spontaneously without any complications, as described by others as well ${ }^{13,21,27}$.

The mechanism and pattern of recurrency after classic surgery differs from the processes following laser ablation ${ }^{10}$. It is well known that, after classic surgery, open side branches and neovascularisation are responsible for recurrency in many cases $4,5,6$. In spite of this, with laser ablation, recanalisation and dilatation of the accessory anterior vein are the reasons for recurrency $28,29,30$. The reason for recanalisation could be that less treatment energy was employed ${ }^{18,31}$. It is thought that these tributaries

\section{References}

1) Howard A, Howard DPJ, Davies AH. Surgical treatment of the incompetent saphenous vein. In: Gloviczki P, editor. Handbook of venous disorders. London: Arnold; 2009. p. 400-8.

2) Perrin MR, Guex JJ, Ruckley CV, dePalma RG, Royle JP, Eklöf B et al. Recurrent varices after surgery (REVAS), a consensus document. Cardiovasc Surg 2000; 8:233-45.

3) Herman $J$ et al. Recurrent varicose veins: causes and neovascularisation. A 17-year experience. Int Angiol. 2015 Feb;34(1):53-9

4) Perrin M. Recurrent varicose veins: etiology and management. In: Gloviczki P, editor. Handbook of venous disorders. London: Arnold; 2009. p. 446-56.

5) Bergan J, Cheng VL. Treatment of recurrent varicose veins by sclerosant foam. In: Bergan J, Cheng VL, editors. Foam Sclerotherapy. London: Royal Society of Medicine Press; 2008. p. 193-7.

6) Jones L, Fraithwaite BD, Selwyn D, Cooke S, Earnshaw JJ. Neovascularisation is the principal cause of varicose recurrence: results of a randomised trial of stripping the long saphenous vein. Eur J Vasc Endovasc Surg 1999; 12:442-5

7) Goldman MP, Bergan JJ, Guex JJ. Sclerotherapy. 4th Ed, Elsevier, Philadelphia, 2007.

8) Zimmet SE. Endovenous ablation. In: Alam M, Nguyern TH. editors. Treatment of Leg Veins. Philadelphia: Elsevier; 2006. p. 147-63

9) Anwar MA, Idrees M, Aswini M, Theivacumar NS. Fate of the tributaries of sapheno-femoral junction following endovenous thermal ablation of incompetent axial vein - A review article. Phlebology. 2019 Apr;34(3):151-155.

10) O'Donnell TF, Balk EM, Dermody M. Recurrence of varicose veins after endovenous ablation of the great saphenous vein in randomized trials. J Vasc Surg Venous Lymphat Disord 2016; 4: 97 105 .

11) Bihari I, Lakner G. Removal of varicose veins using Smetana's saw-knife. In: Negus D, Jantet G, editors. Phlebology '85. London, Paris: John Libbey Co. 1986. p. 182-4.

12) Bihari I, Ayoub G, Bokros S, Bihari P. Laser surgery on varicose veins. Magy Seb. 2018 Sep;71(3):134-141. participate in the drainage of venous blood in the abdominal wall $^{26,32}$. We and colleagues with similar results ${ }^{23}$ did not find any dilatation in the vein of that region. During our follow-up period there were no signs of neovascularisation. According to other experience, the good results at one year continue to last ${ }^{8,33,34}$.

\section{Conclusions}

Flush closure and short stump gave better early results than the formerly recommended technique. There is not a higher risk of complications if the junction is occluded flush with the femoral vein.

13) Morrison N. Laser treatment of the incompetent saphenous vein. In: Gloviczki P, editor. Handbook of venous disorders. London: Arnold; 2009. p. 418-28.

14) Van den Bos RR, Kockaert MA, Neumann HAM, et al. Technical review of endovenous laser therapy for varicose veins. Eur J Vasc Endovasc Surg 2008;35:88-95.

15) Corcos L, Dini S, De Anna D, et al. The immediate effects of endovenous diode $808 \mathrm{~nm}$ laser in the greater saphenous vein: Morphologic study and clinical implications. J Vasc Surg 2005; 41: 1018-25.

16) Marangoni O, Longo L. Lasers in Phlebology. Trieste: Edizioni Goliardiche; 2006.

17) Huang $Y$, Jiang $M$, Li W, Lu X, Huang $X$, Lu $M$. Endovenous laser treatment combined with a surgical strategy for treatment of venous insufficiency in lower extremity: A report of 208 cases. J Vasc Surg 2005;42:494-501.

18) Proebstle TM, Sandhofer M, Kargl A, Gul D, Rother W, Knop J, et al. Thermal damage of the inner vein wall during endovenous laser treatment: key role of energy absorption by intravascular blood. Dermatol. Surg 2002; 28(7):596-600.

19) Bihari I. A turning point in the invasive treatment of lower limb varicosity. Orv Hetil. 2018 Dec;159(52):2195-2201

20) Corcos L, Dini S, Peruzzi G, et al. Duplex Ultrasound Changes In The Great Saphenous Vein After Endosaphenous Laser Occlusion With 808-Nm Wavelength. J Vasc Surg 2008;48:1262- 71

21) Gradman WS. Adjunctive proximal vein ligation with endovenous obliteration of great saphenous vein reflux: does it have clinical value? Ann Vasc Surg 2007;21:155-8.

22) Chandler JG, Pichot O, Sessa C, Schuller-Petrovic S, Osse FJ, Bergan JJ. Defining the role of extended saphenofemoral junction ligation: a prospective comparative study. J Vasc Surg 2000;32:941-53.

23) Theivacumar NS, Dellagrammaticas D, Beale RJ, Mavor Al, Gough MJ. Fate and clinical significance of saphenofemoral junction tributaries following endovenous laser ablation of great saphenous vein. Br J Surg 2007;94:722-5.

24) Theivacumer NS, Dellagrammaticas D, Beale RJ, Mavor AI, Gough MJ. Factors influencing the effectiveness of endovenous laser ablation (EVLA) in the treatment of great saphenous vein reflux. Eur J Vasc Endovasc Surg 2008;35: 119-23. 
I Bihari, F Zernovicky, P Dragic, G Ayoub, S Bokros, P Bihari - Flush closure of the sapheno-femoral junction with LASER

25) Francheschi C, Zamboni P. Principles of venous hemodynamics. Nova, New York, 2009.

26) Gerard JL. What is new in laser treatment of the saphenous and perforating veins? In: Gloviczki P, Shields RC, Bjarnason H, Becquemin JJ-P, Gloviczki ML, editors. Mayo Clinic International Vascular Symposium 2011. Torino: Minerva Medica; 2011. p. 349-54.

27) Mozes G, Kalra M, Carmo M, Swenson L, Gloviczki P. Extension of saphenous thrombus into the femoral vein: A potential complication of new endovenous ablation techniques. J Vasc Surg 2005;41:130-5.

28) Proebstle TM. Endovenous laser for saphenous vein ablation. In: Bergan J, editor. The Vein Book. Amsterdam, Boston, Heidelberg, London: Academic Press; 2007. p. 267-73.

29) Soumian S, Davies A. Endovenous management of varicose veins. Phlebology 2004;19:163-9.
30) Perrin M. Endoluminal treatment of lower limb varicose veins by endovenous laser and radiofrequency techniques. Phlebology 2004; 19:170-8.

31) Proebstle TM, Moehler T, Gül D, Herdemann S. Endovenous treatment of the great saphenous vein using a 1,320 nm Nd:YAG laser causes fewer side effects than using a $940 \mathrm{~nm}$ diode laser. Dermatol Surg 2005;31:1678-83.

32) Agus GB, Mancini S, Magi G, IEWG. The first 1000 cases of Italian Endovenous-laser Working Group (IEWG). Rationale, and long-term outcomes for the 1999-2003 period. Int Angiol 2006;25:209-15.

33) Min RJ, Khilnani N, Zimmet SE. Endovenous laser treatment of saphenous vein reflux: long- term results. J Vasc Interv Radiol 2003;14:991-6.

34) Willenberg T. Some thoughts before an epidemic of endoluminal varicose vein ablations Phlebologie 2009;38: 1-2. 